\title{
Clutch System - How to prevent warranty issues thru proper manufacturing and installation - Import compilation of Product Engineering Lesson Learned.
}

\author{
Marcio Caçula
}

General Motors

\begin{abstract}
The purpose of this article is emphasize how a suitable Manufacturing can influence and guarantee the functionality of Clutch System - Clutch Cover, Clutch Disc and some components from hydraulic System, for example, Concentric Slave Cylinder - CSC. The most people or most of customers in our Market does not know what we have behind of Clutch Pedal. The major function of Clutch System would be an interruptible coupling between the engine and manual transmission, in simple terms the idea would be provide torque, torque interruption, provide comfort during the launch of vehicle and also attenuate the combustion engine s irregularities. In the meantime, behind of this concept, function of the product, there is an import manufacturing operation that if not carry out accordingly among the O\&M companies, can jeopardize the product, reduce lifetime and consequently to have issues in the field (customer satisfaction).

In parallel, we would like to share all Lesson Learned that we got thru the years with new Engineers and offer to the market the Best Practice in terms of Manufacturing for Clutch System.
\end{abstract}




\section{INTRODUCTION}

This work objective is to offer evidences from several different issues that the Clutch System application should take into consideration during manufacturing operation and provide learnings that could avoid several potential issues during assembly line phase.

\section{Identify Clutch System Components}

Powertrain

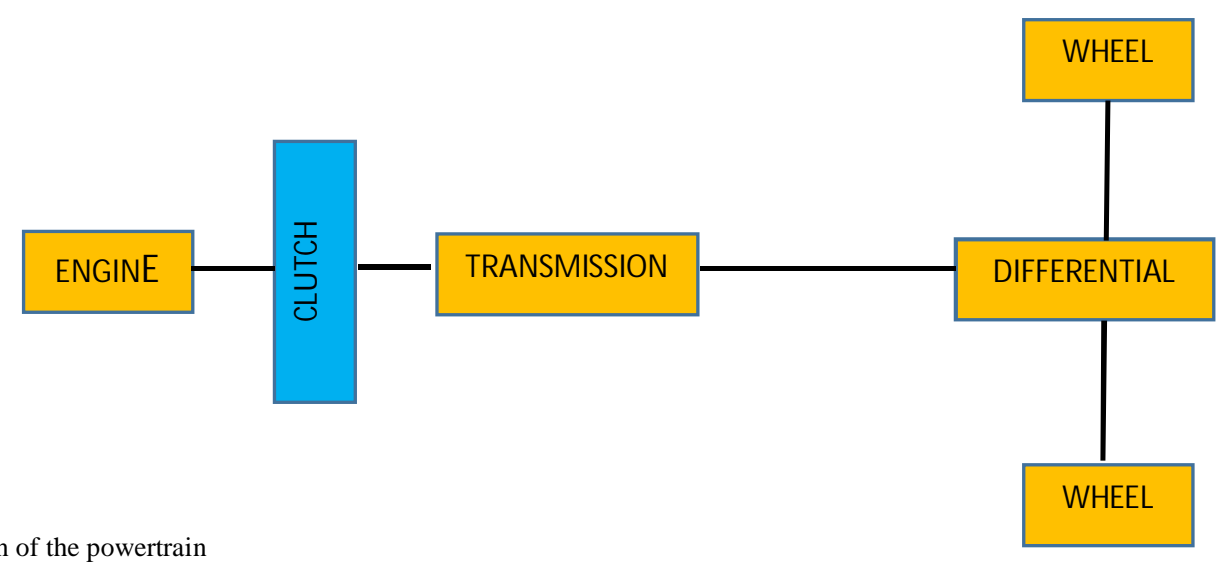

Figure 1 - Illustration of the powertrain

Clutch Cover

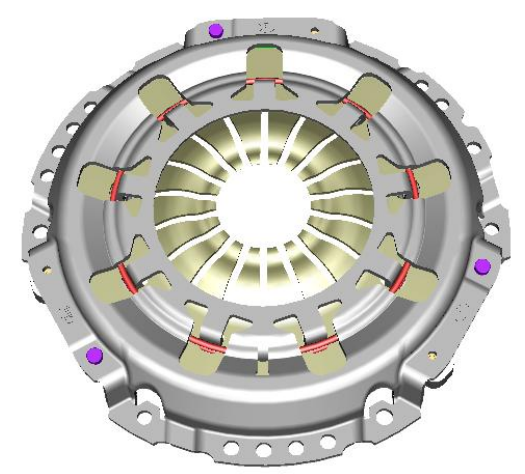

Figure 2 - clutch cover

Source - Shaeffler Group

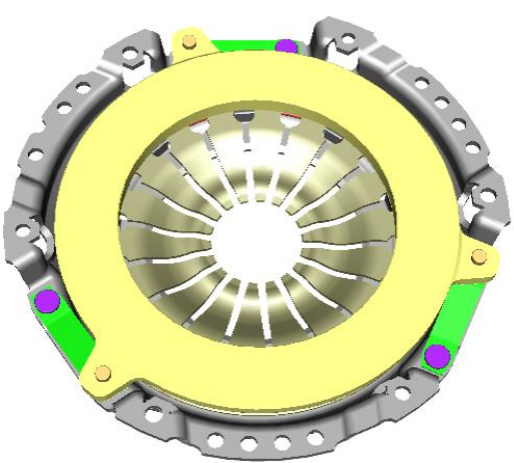

Figure 3 clutch cover - pressure plate 


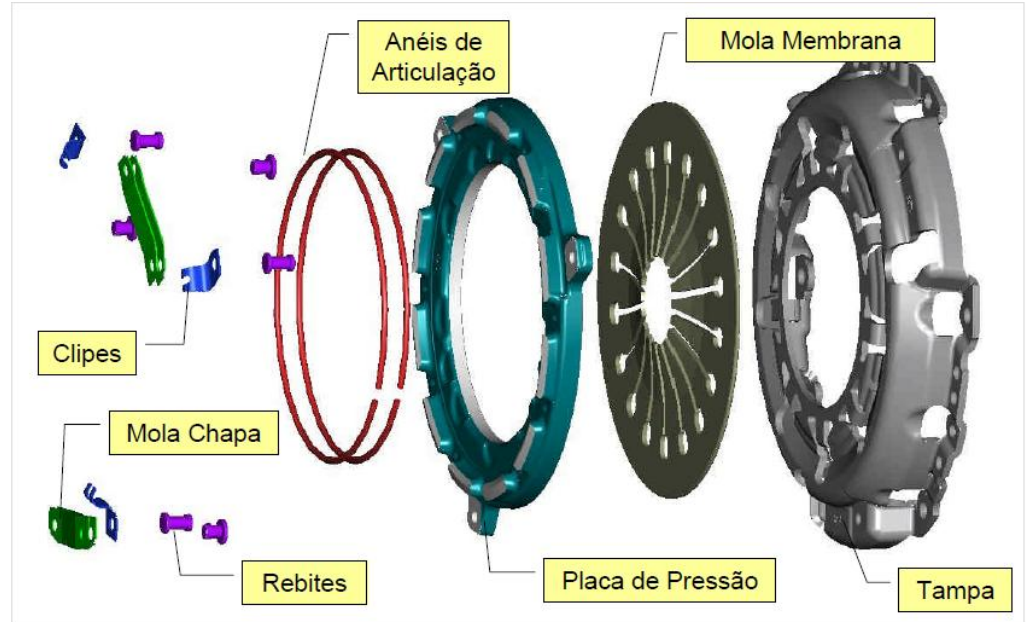

Figure 04 - clutch cover - components

Clutch Disc - Torsional Damped Disc - TDD

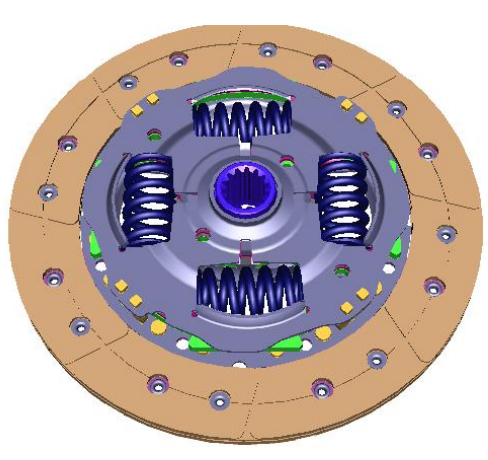

Figure 05 clutch disc

Source - Shaeffler Group

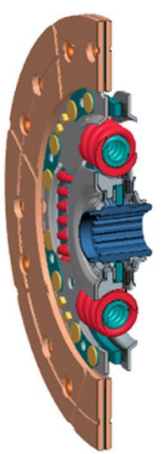

Figure 06 clutch disc session A-A 


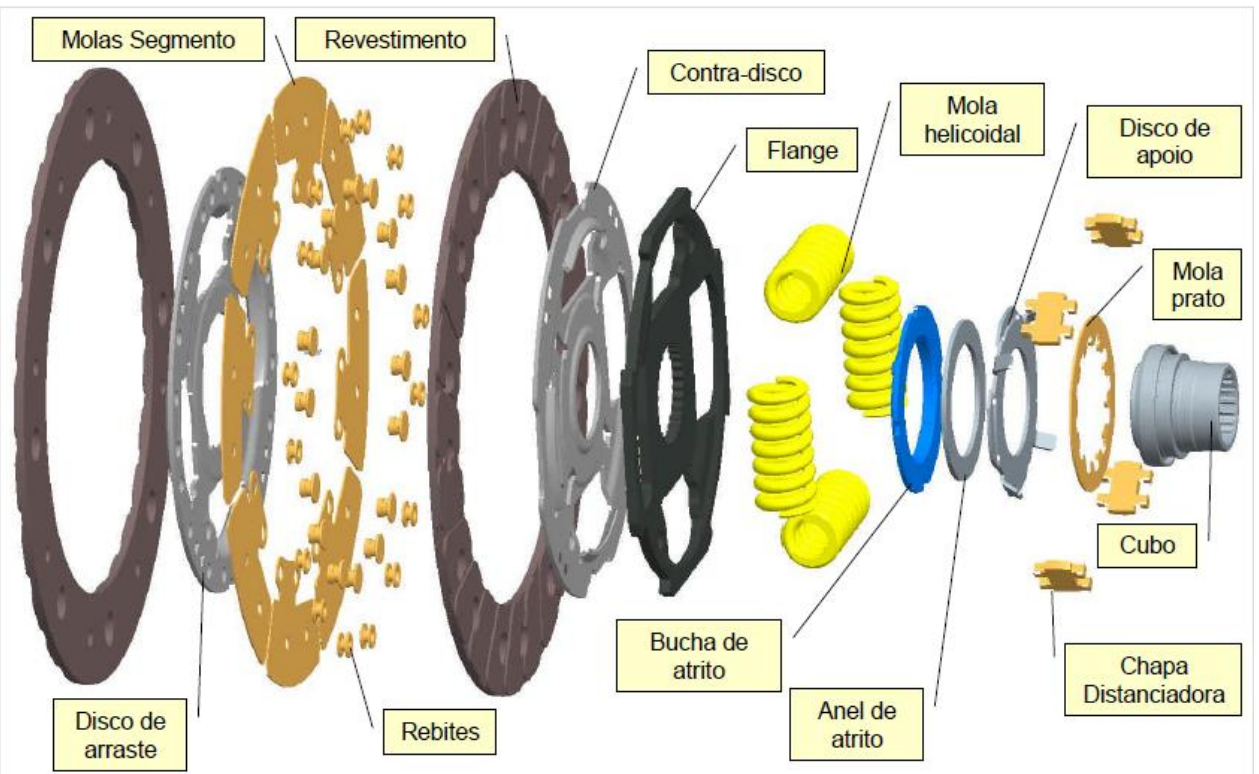

Figure 07 - Clutch disc - components

\subsection{Packaging \& Handling a Clutch Set}

In General a clutch Set arrives from the Suppliers in racks packed in a way protect the product. There will be an operator that will take the clutch cover \& clutch disc through a special gage for this operation with main goal to assemble in the engine. Please see pictures below from the racks and assemble in the engine, plus special gage.

In the meantime, there are assembly lines totally automatic and for this operation there is no need the operator handle the Clutch Set, obviously it depends of the volume and cost involved.

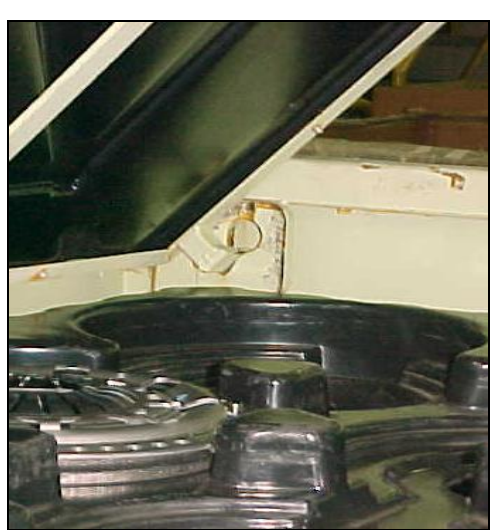

Picture 08 \& 09 rack
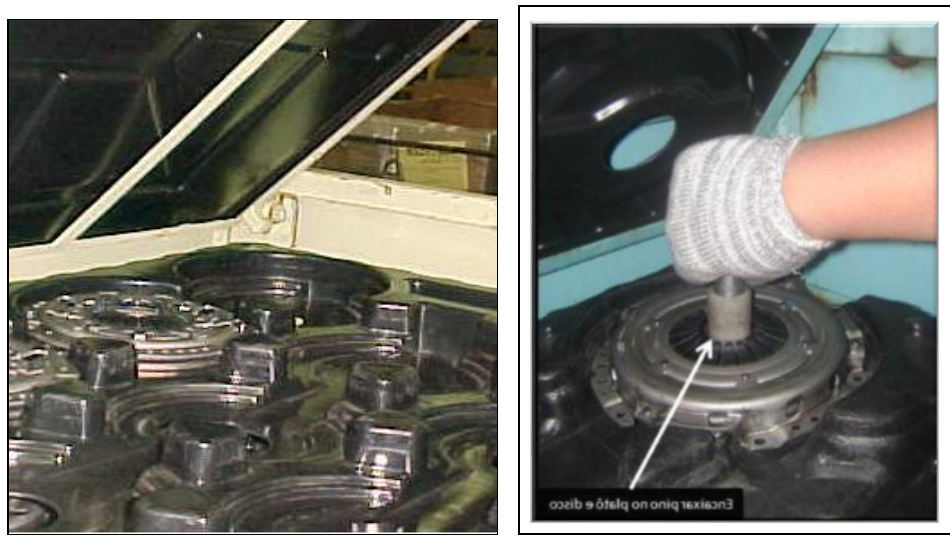

Picture 10 operator using special gage to pick-up the parts 


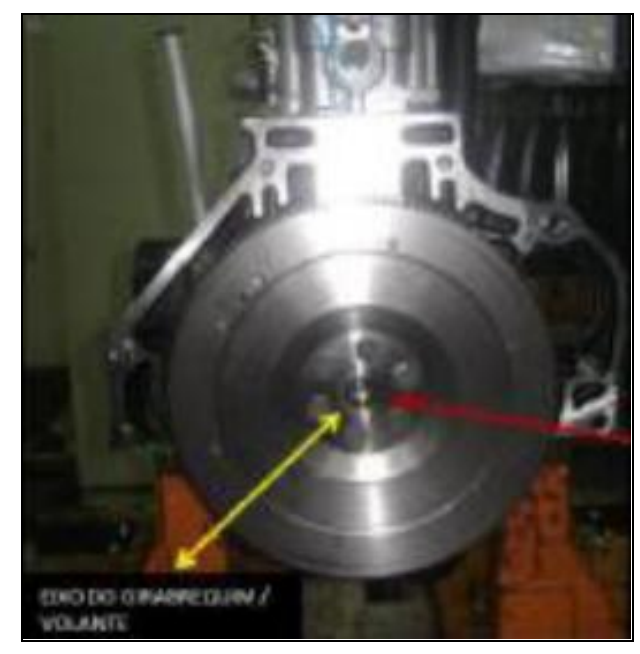

Picture 11 flywheel

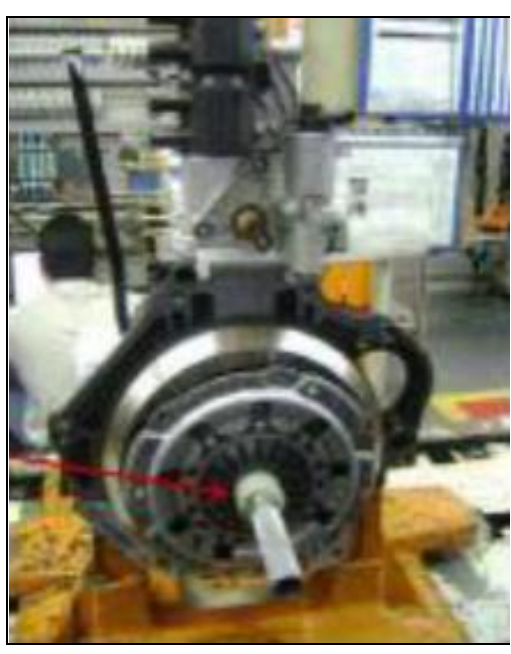

picture 12 clutch set assembled with gage
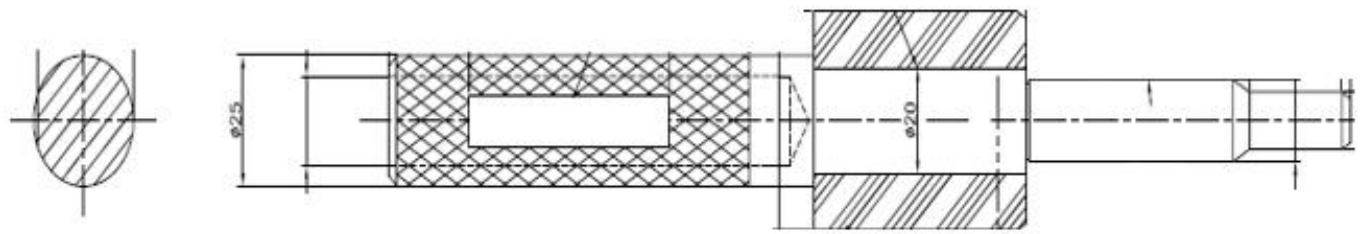

SECTION A-A

Figure 13 example of gage to assemble the clutch set

\subsection{Be Careful with handling the parts}

Clutch Set needs special attention during the assemble Process. For example, if accidentally the clutch cover fall downs on the ground, this part must immediately segregated due to the fact the clutch cover has got a spring strap. This component has a function to guarantee the return of pressure plate. If the spring strap fall downs on the ground probably it will be damage and after assembled, during the tests with vehicle, there will not be possible the gearshift of the vehicle.

It would be generate a Quality Issue, probably the production would have a build stop, Tthe Supplier would be contacted immediately and probably would receive a kind of demerit until found out the root-cause.

Therefore, all operators must trained to avoid this failure mode. 

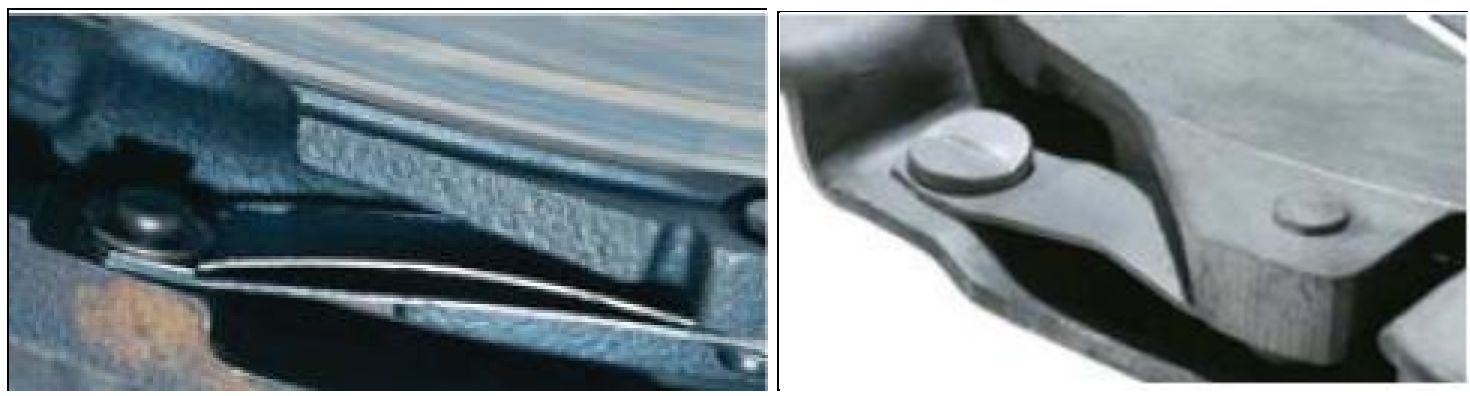

Pictures 14 \& 15 spring damaged

\section{Counter Force Free}

After mounting Clutch Disc and Clutch Cover in the engine, is necessary screw 06 bolts on the flywheel and installation condition disengaged. If we do not make this operation this way, we will lost run-out and more than this, we can loss the operation point. The consequence in the field (warranty) would be several items such as judder and may have to jeopardize the csc - concentric slave cylinder or have to repair the clutch set as well. For sure that this operation called CFF is most import during assemble Process.

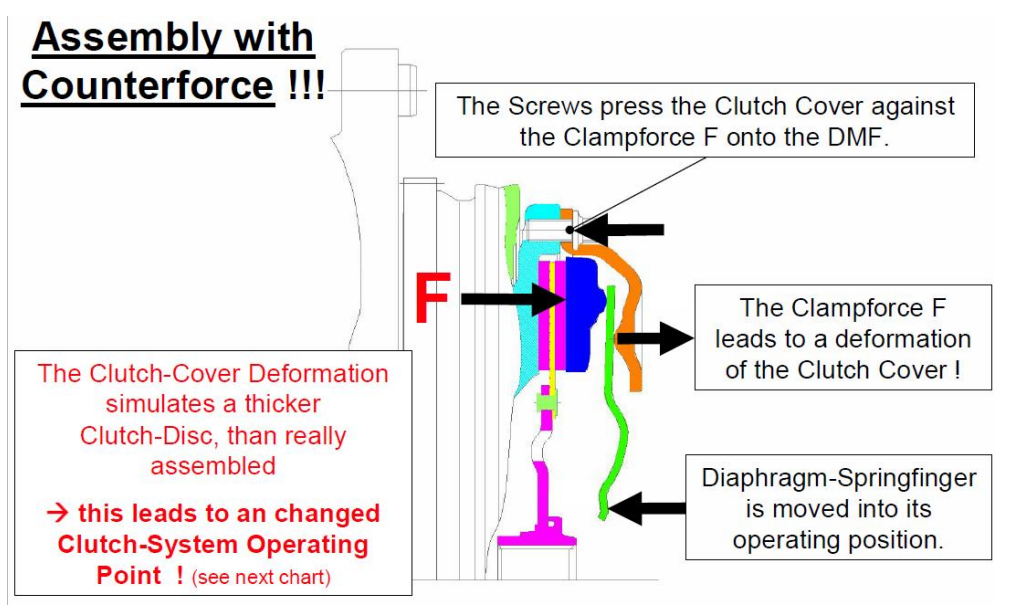

Figure 16 - Counter Force Free 


\section{Impact of Assembly with Counterforce}

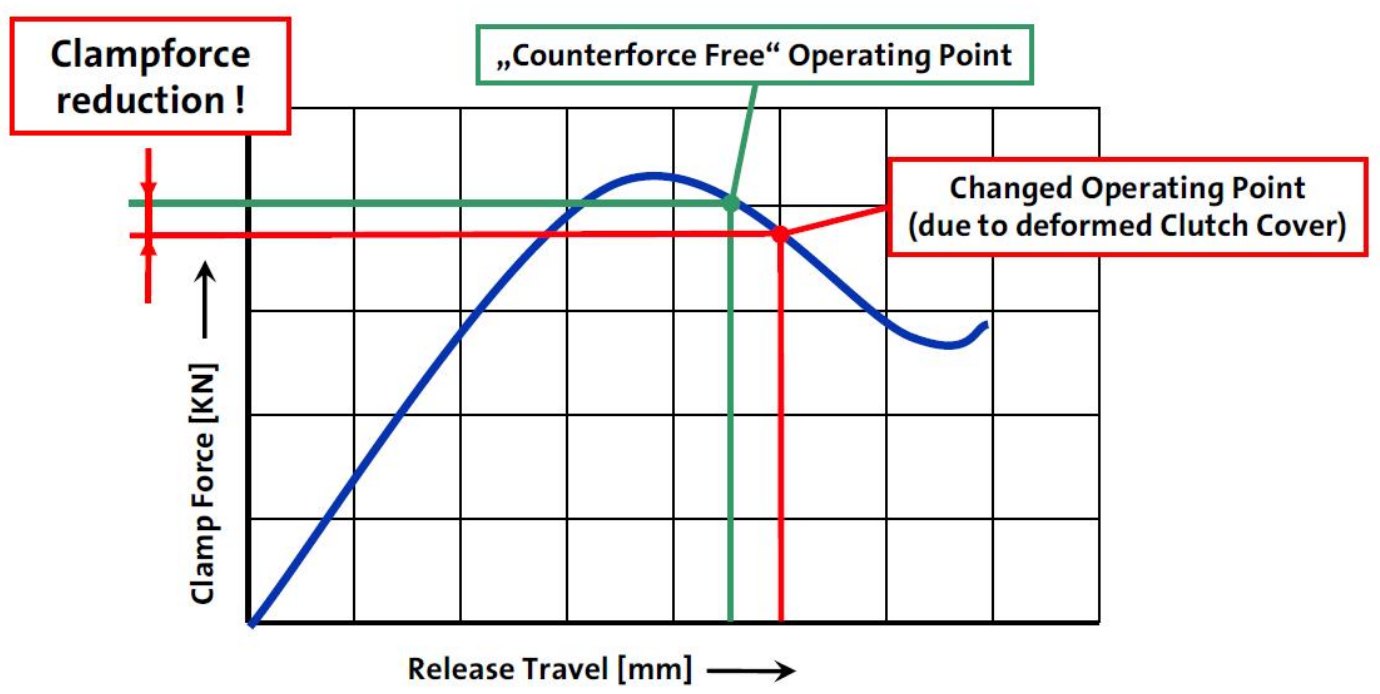

Figure 17 - The graphic shows the importance of CFF

See below some pictures regarding exactly moment in the condition disengaged and screw the bolts.

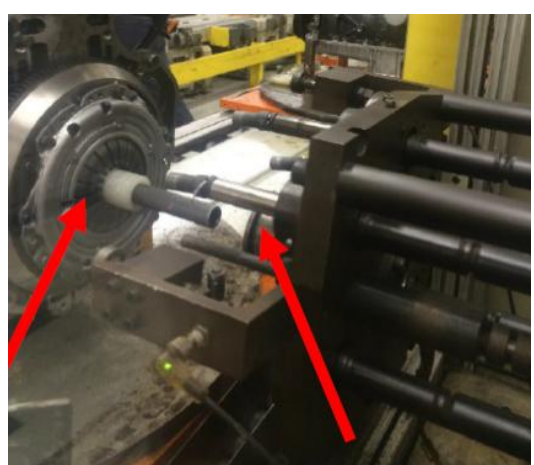

Pictures 18 before CFF

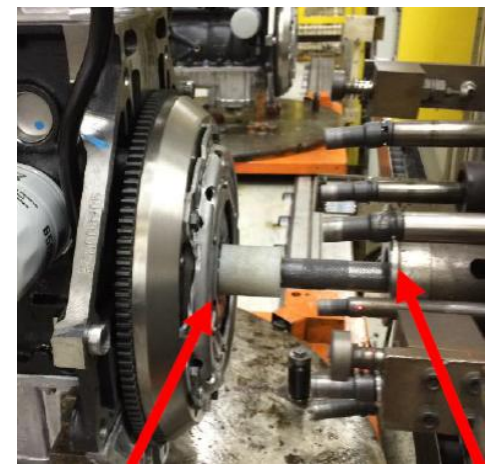

Picture 19 piston being applying

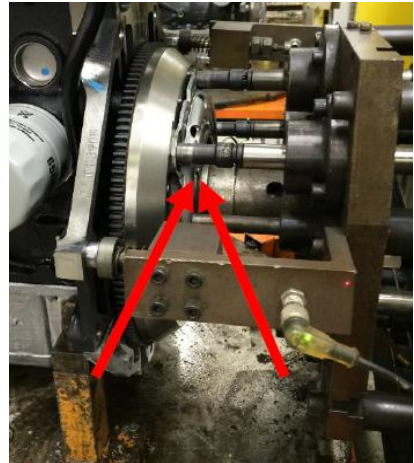

Picture 20 diaphragm spring disengaged

\subsection{If Rework is necessary - special too is mandatory}

After CFF the operator will take off the gage from Clutch Disc hub and the Process Flow will be finish as usual. In the meantime, if there is a need to rework some engine, then a special too must applied to remove the Clutch Set. There is a need to fixing 04 screws on engine block, please see pictures below: 

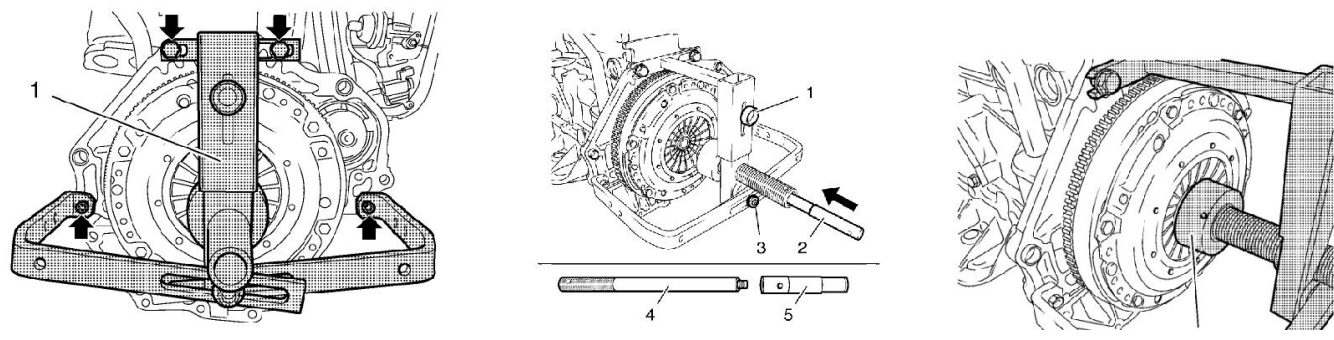

Figures 21 until 23 showing the diaphragm spring being disengaged

\section{Misalignment}

This topic could be reflect in repair of clutch disc and complaints regarding rtattle noise in the field, if we do not apply accordingly the merge between engine and transmission. The tolerance between centers should not exceed $\pm 0,2 \mathrm{~mm}$. We have the dowel pin in the block engine to guarantee the merge. Please see the pictures 23 until 28. Other point very import to check during Assembly Process, would be when the Operator apply only 01 bolt and apply the torque, than will be a displacement between Transmission input shaft \& Clutch Disc, jeopardizing Pre damper of Clutch Disc. Regarding this last subject, we provided reproduced the failure mode at Proving Ground. Please see pictures $29,30 \& 31$.

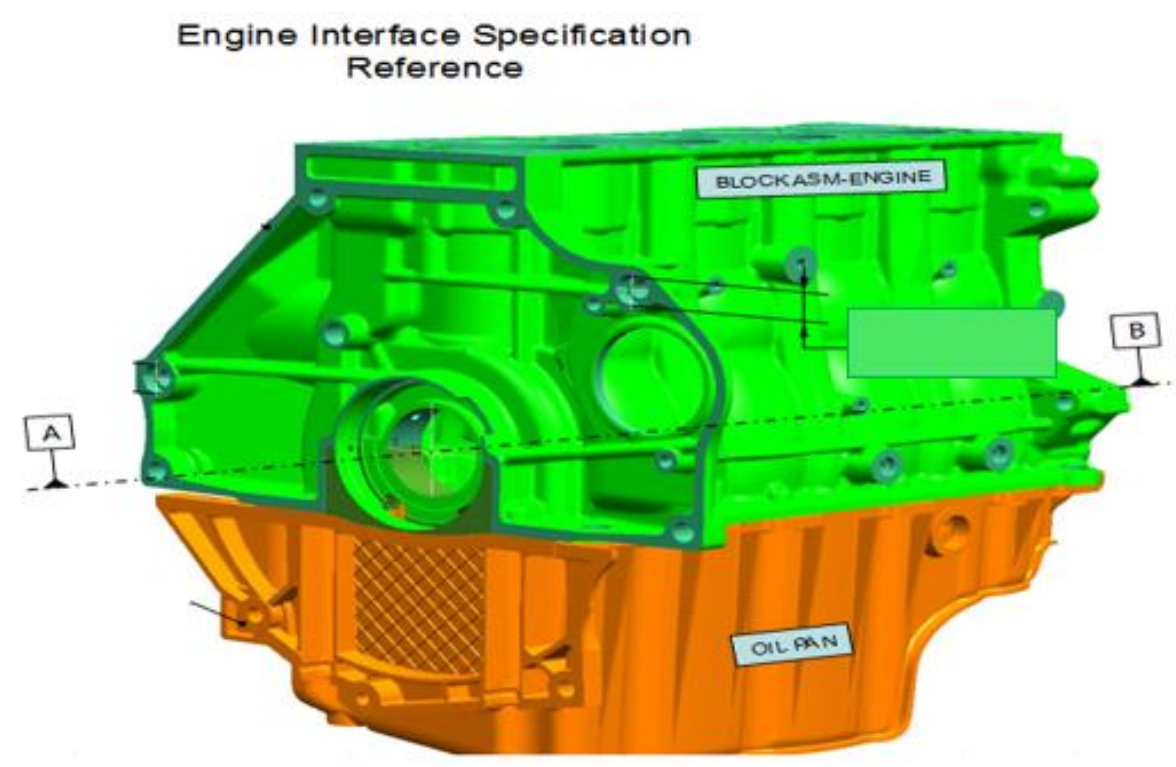

Figure 24 shows the block engine with reference dowel pins position 


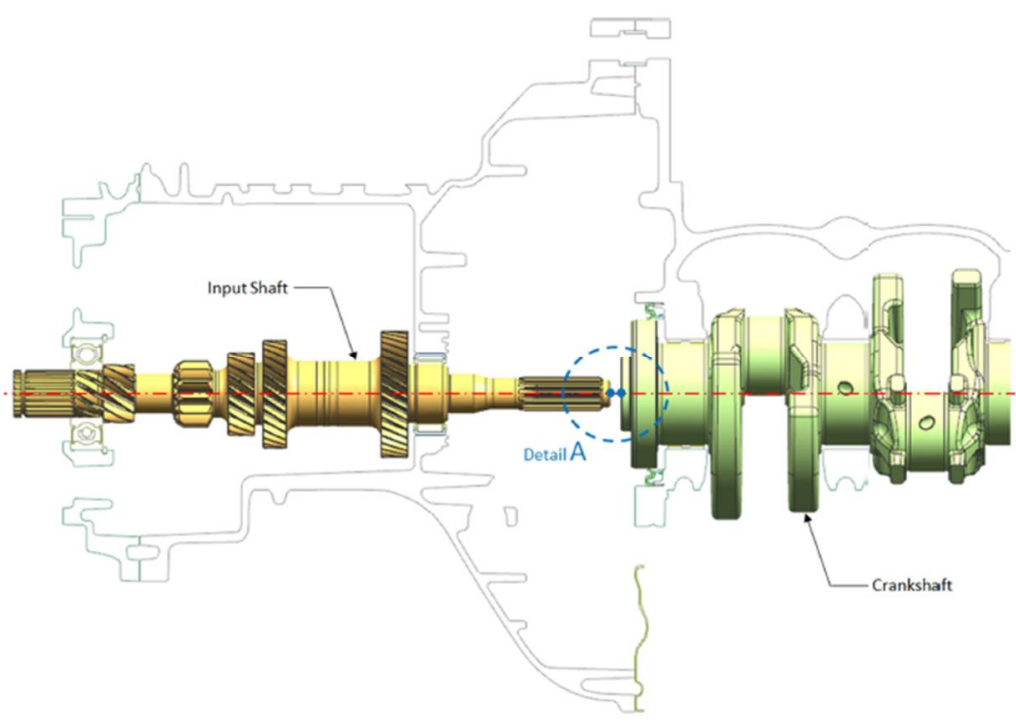

Figure 25 shows the alignment between crankshaft \& input shaft

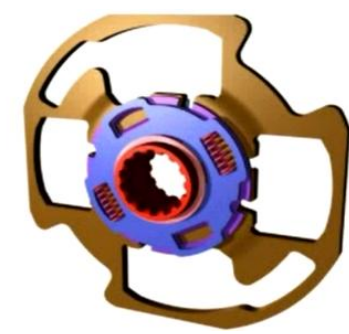

Figure 26 pre-damper of Clutch Dise

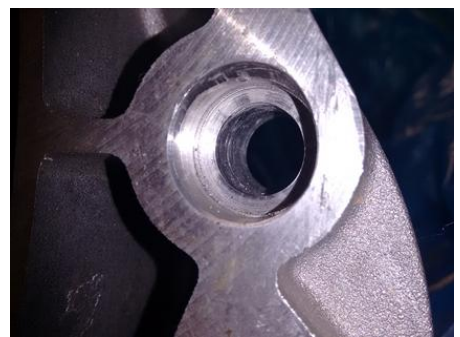

Picture 27 dowel pin damaged

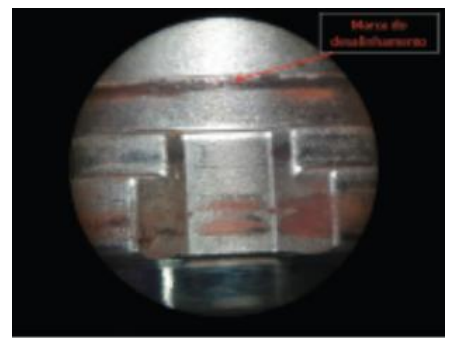

Picture 28 clutch disc hub damage

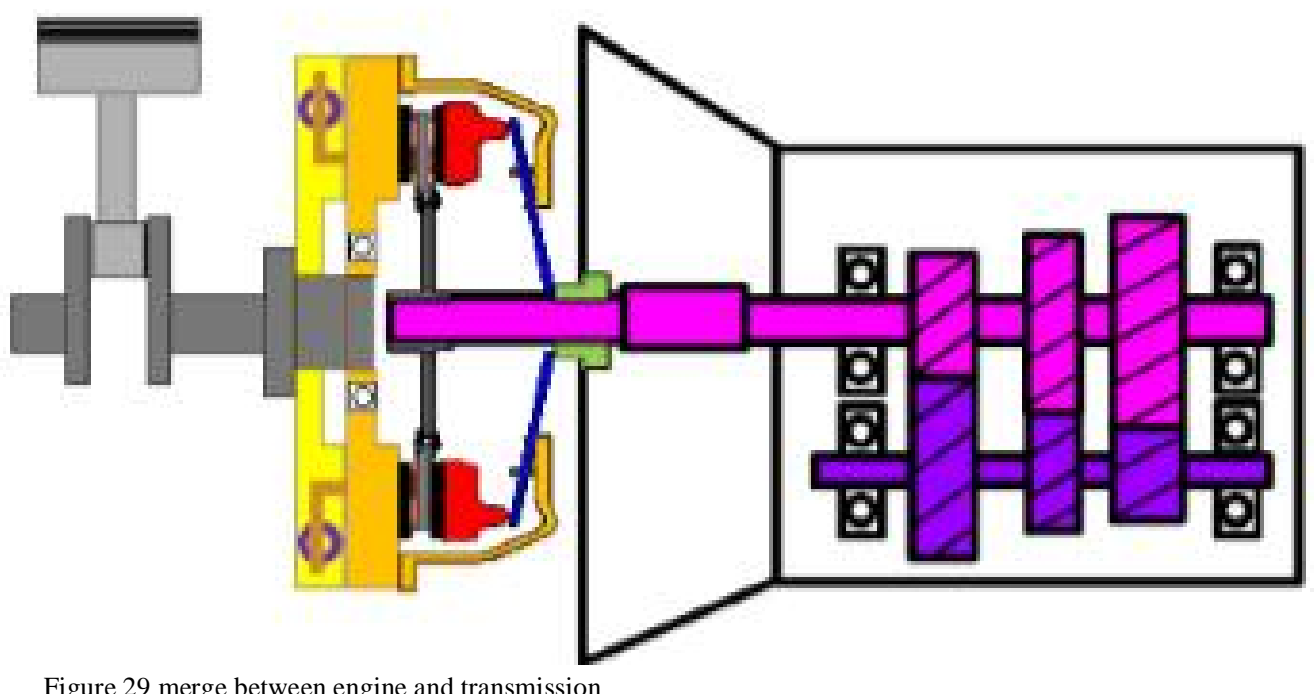

Figure 29 merge between engine and transmission 
Idle with consumers
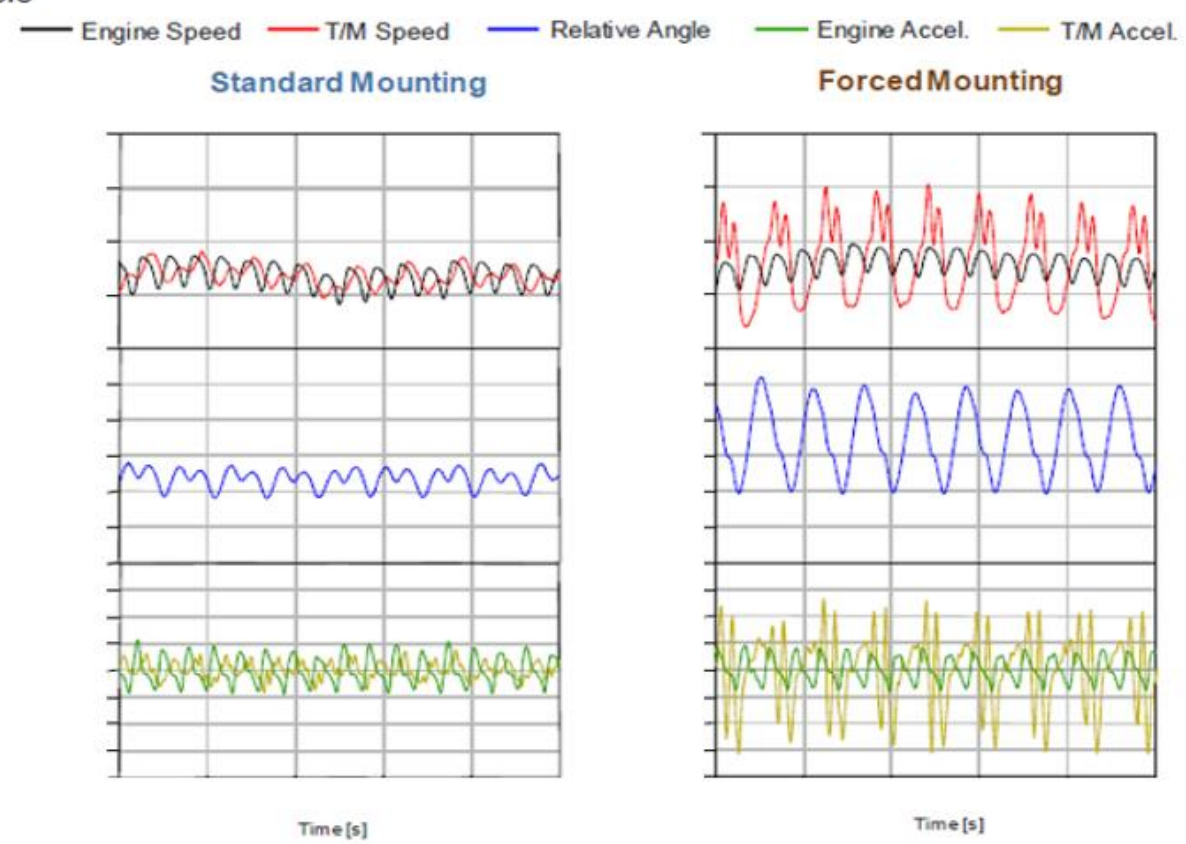

Figure 30 measurement showing merge not accordingly provoking rattle noise - idle condition

\section{Creeping $2^{\text {no }}$ Gear with Consumers}

- Engine Speed -T/M Speed

Standard Mounting

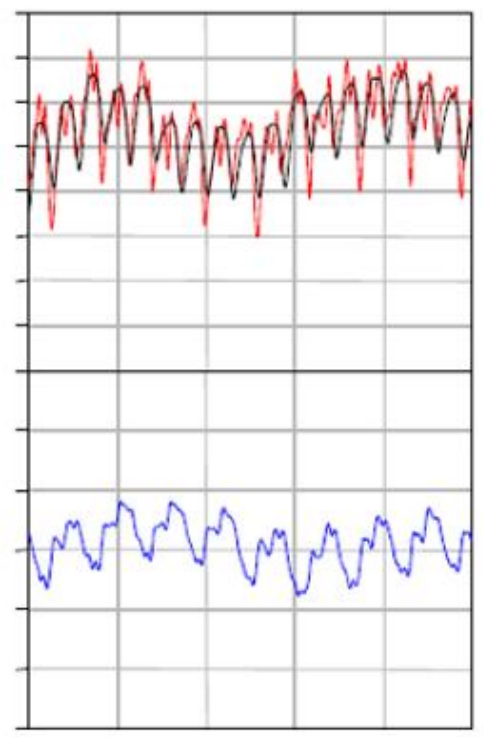

Time [s]
ForcedMounting

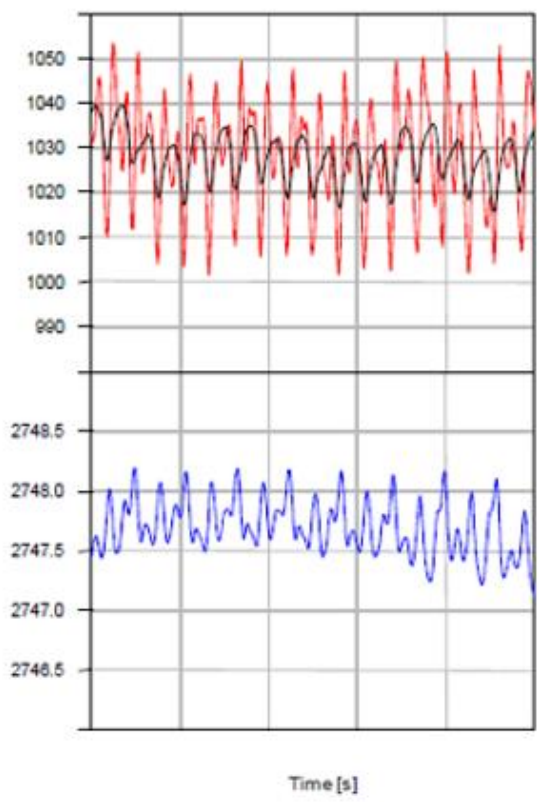

Figure 31 showing the same phenomenon in creeping $2^{\text {nd }}$ gear 


\section{Grease - Enemy Number 1 for Clutch}

This is touchy topic, because is mandatory to lubricate the input-shaft but the problem always is regarding the quantity and how apply it.

Now is available to apply a small quantity on the clutch disc hub instead of input shaft. It would be an improvement in the process flow and we can describe the advantages:

- Avoid waste of grease;

- Mitigate the cases in the field (warranty) because when applied a quantity not accordingly, the grease spread out on clutch disc and the will reach the facing material, then we will have quickly increase temperature and slippage will occur;

- In terms ergonomic will be an improvement, because the recommendation would be an automatic gun ( better for the operator )

\section{CRS - Clutch Release System}

In very simple terms, the CRS is responsible to "open" the clutch and this way is possible change the gear. There is a Clutch Master Cylinder - CMC applied in clutch pedal, than there will be a stroke, the fluid will be compressed through the pipes until CSC the will apply a force against diaphragm spring and "open" the clutch. In the meantime, we have also to take care with some aspects during the assembly line, mainly with CSC

The figure 32 below is correlated the CRS system.

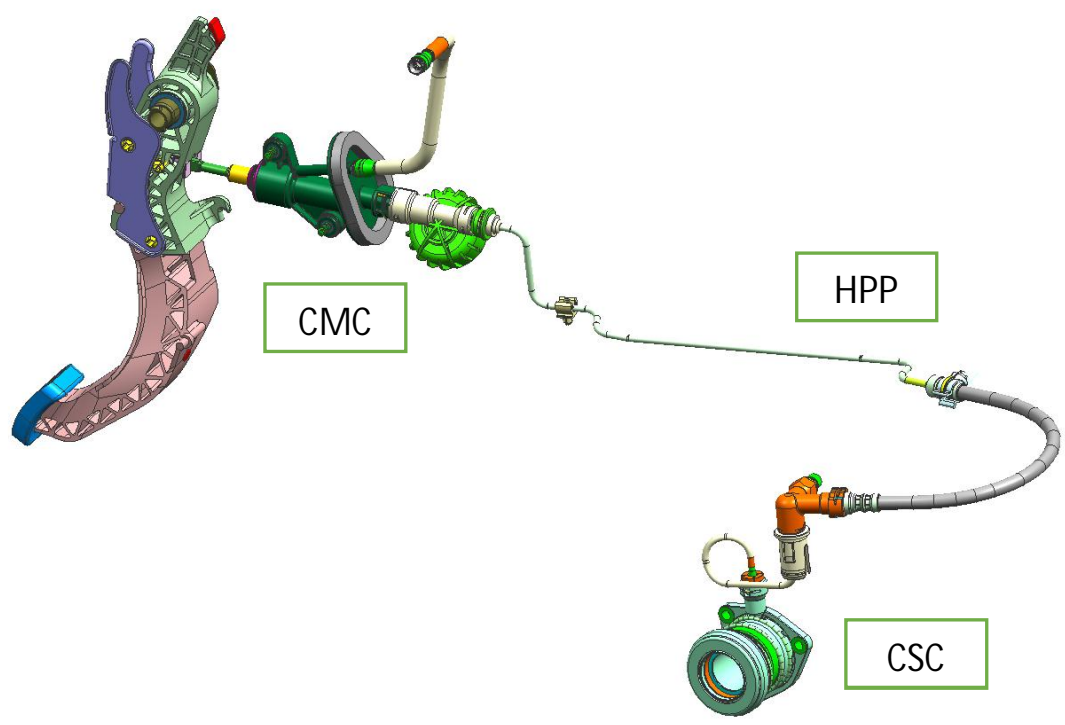

In a specific case from CSC, the misalignment can contribute to failure this component, also we can describe the we need apply the correct grease in the oring inside transmission because we can provoke swollen seal. 


\section{Takeaway}

It is very import that all specifications from Product Engineering and all lesson s learned be shared and aligned with Manufacturing Process. It means that a lot of money can be saved and avoid dislike and issues in the field that could be affect the most value asset, The customer. Finally the Manufacturing Process has an influence on the Clutch System and your functionality.

In parallel other factors that could jeopardize the product clutch set / durability

Factors that influence a durability
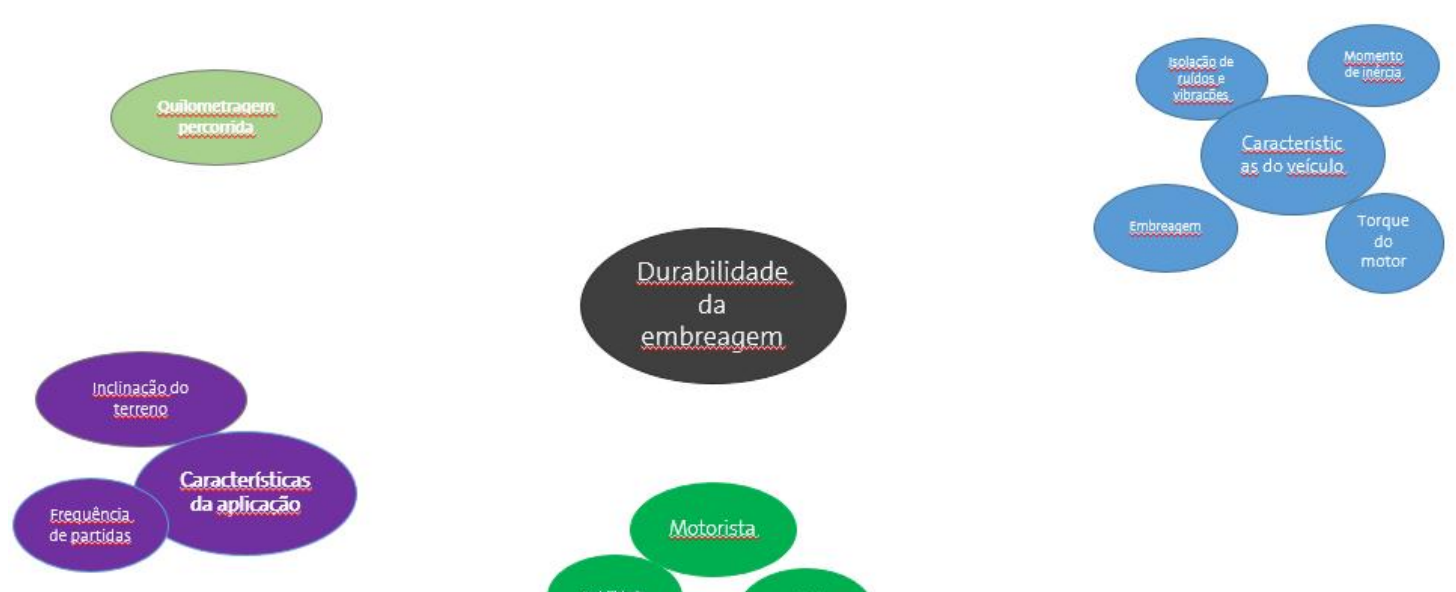

Figure 33

Source - ZF Sachs
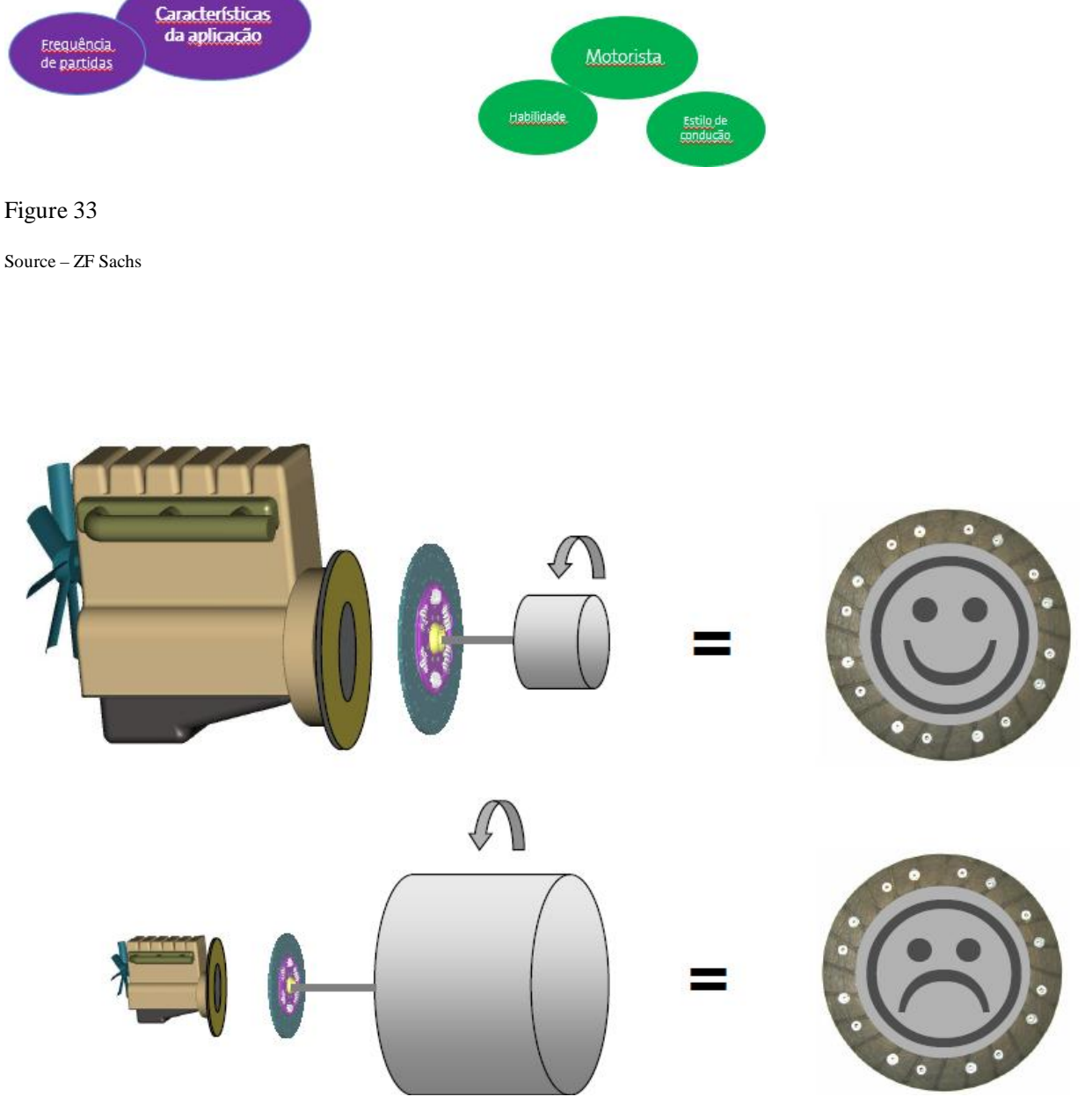

Figure 34 - Torque vs inertia 


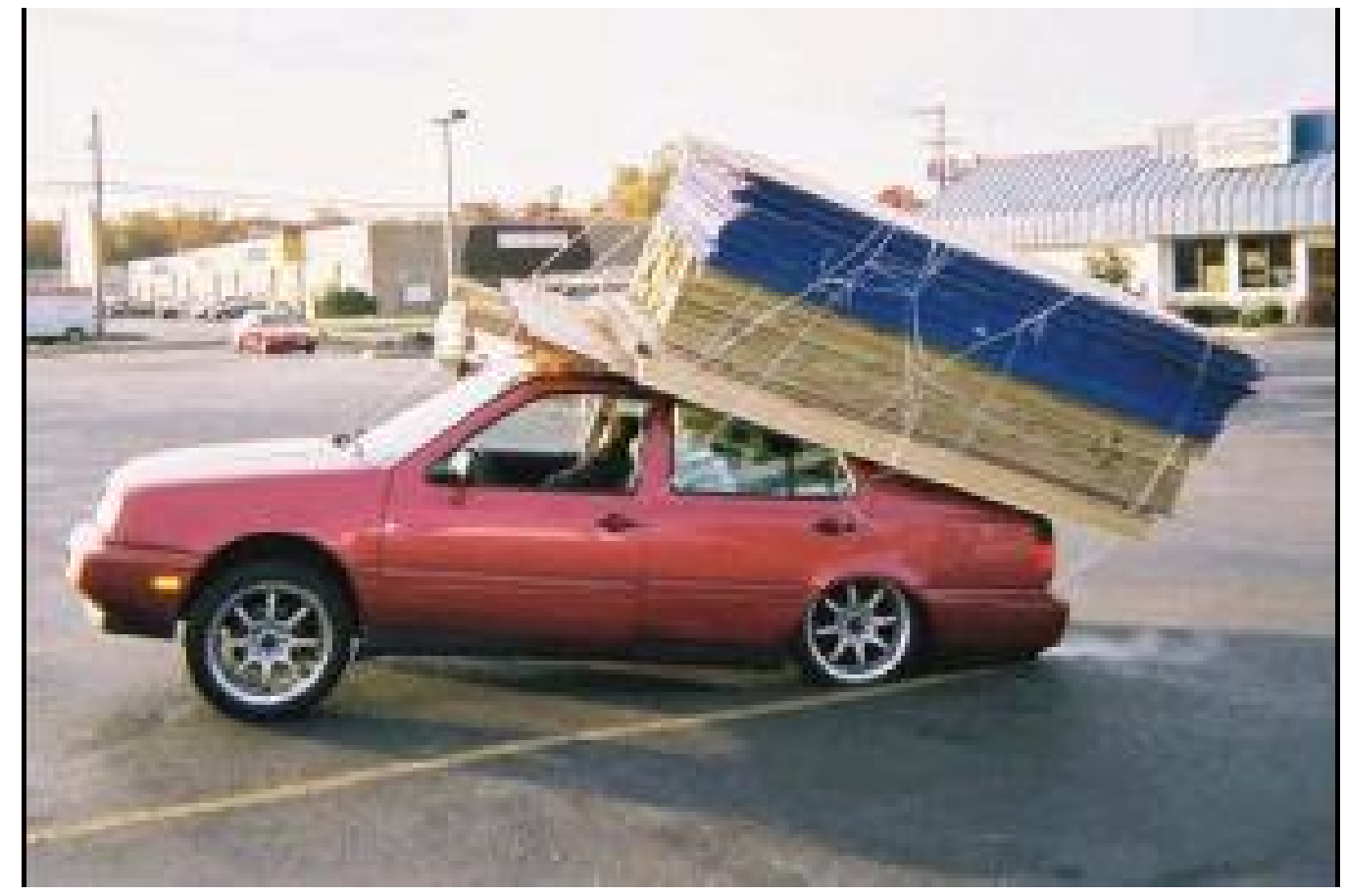

Picture 35 - inertia vs total gross weight

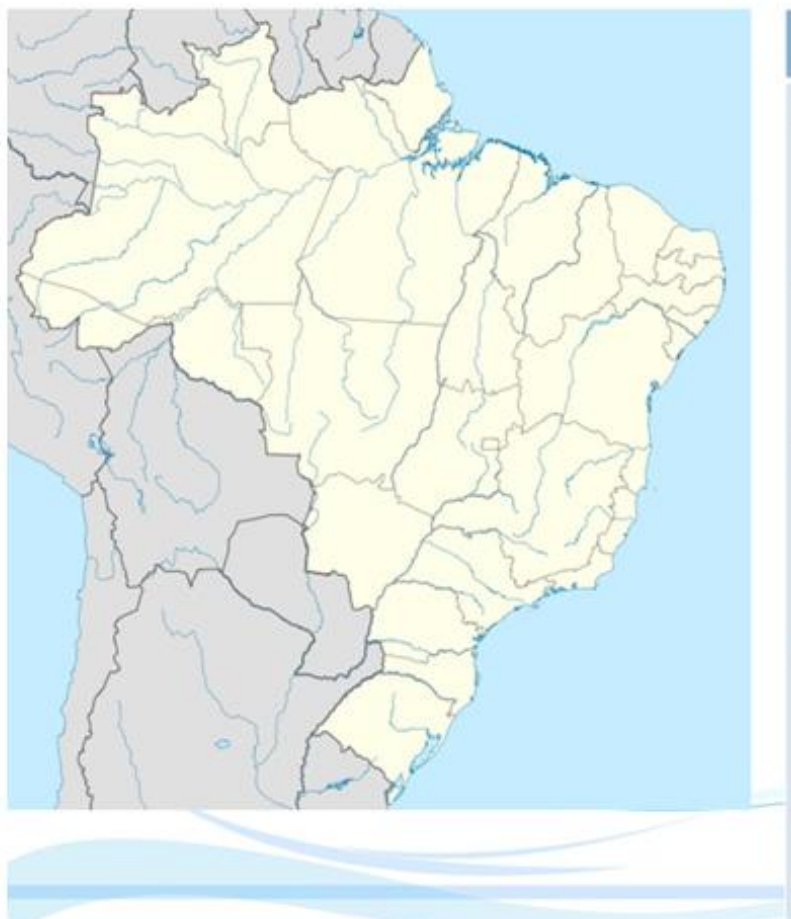

\section{Brazil}

\section{Temperature:}

- $\min .=-17^{\circ} \mathrm{C}-$ Urubici / SC

- $\max .=+45^{\circ} \mathrm{C}-$ Bom Jesus / PI

\section{Altitude:}

- average $=1000 \mathrm{~m}$

- $\max .=1628 \mathrm{~m}$ Campos do Jordão

\section{Brazilian Coast:}

- length $=7,408 \mathrm{~km}$

- region fully on marine condition

- engine on max. torque condition

\section{Environment:}

- water intrusion

- dust condition

- mud condition

- beach sand

- snow condition

- high up hill condition

- heavy traffic of the big cities;

Figure 36 - Brazil map 

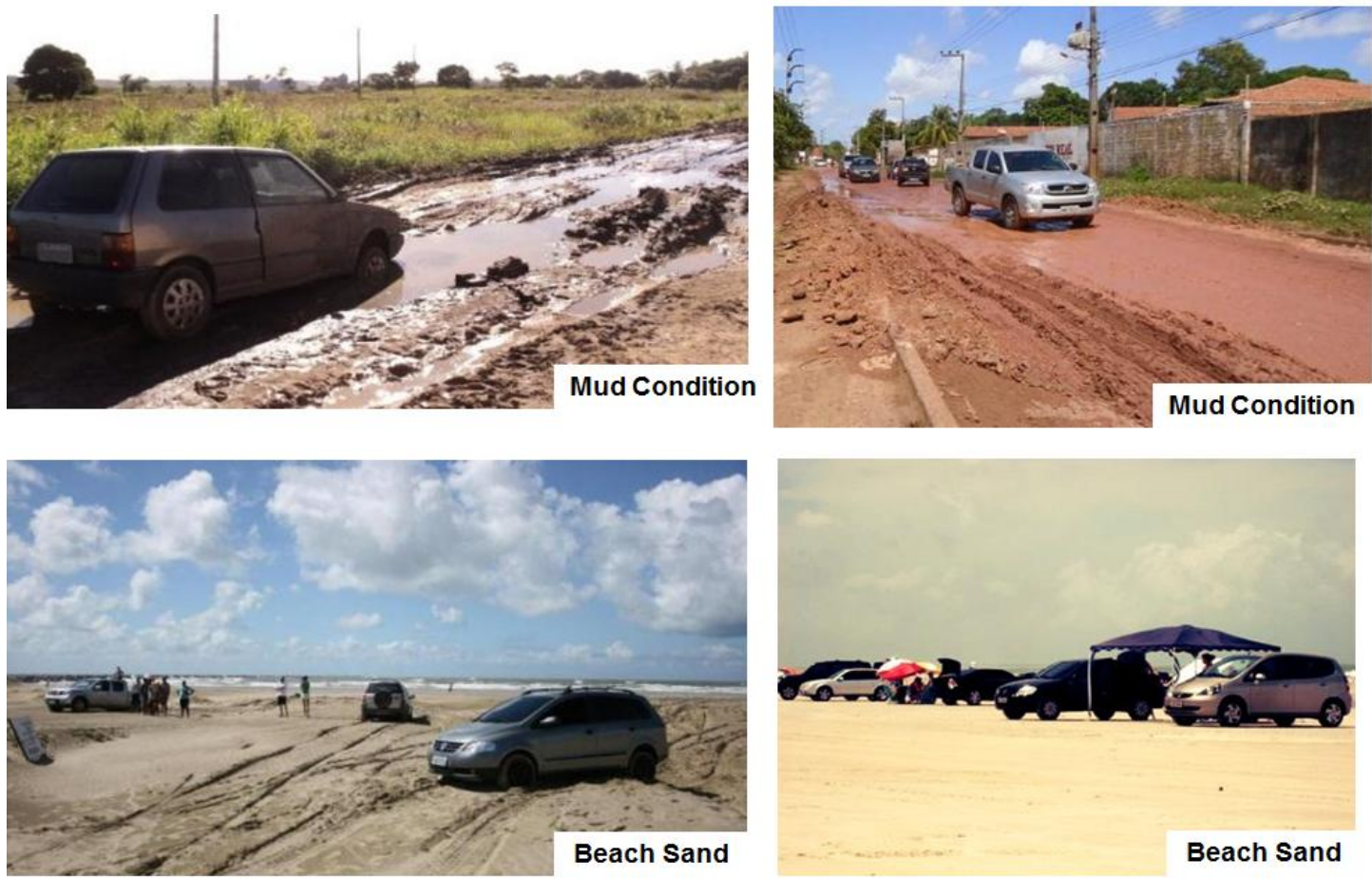

Pictures $37,38,39 \& 40$ - factors that influence the durability
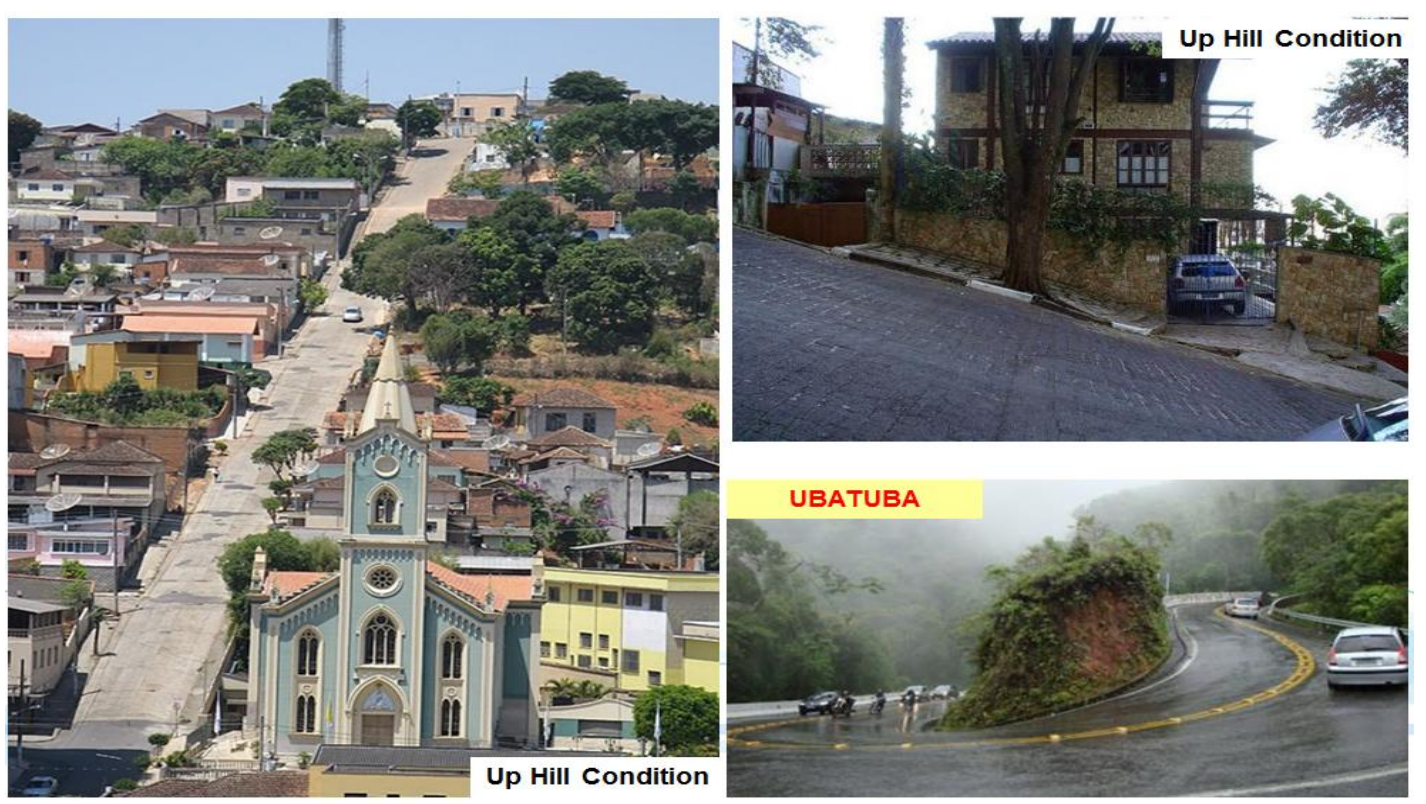

Pictures 41, $42 \& 43$ - Up Hill Condition 

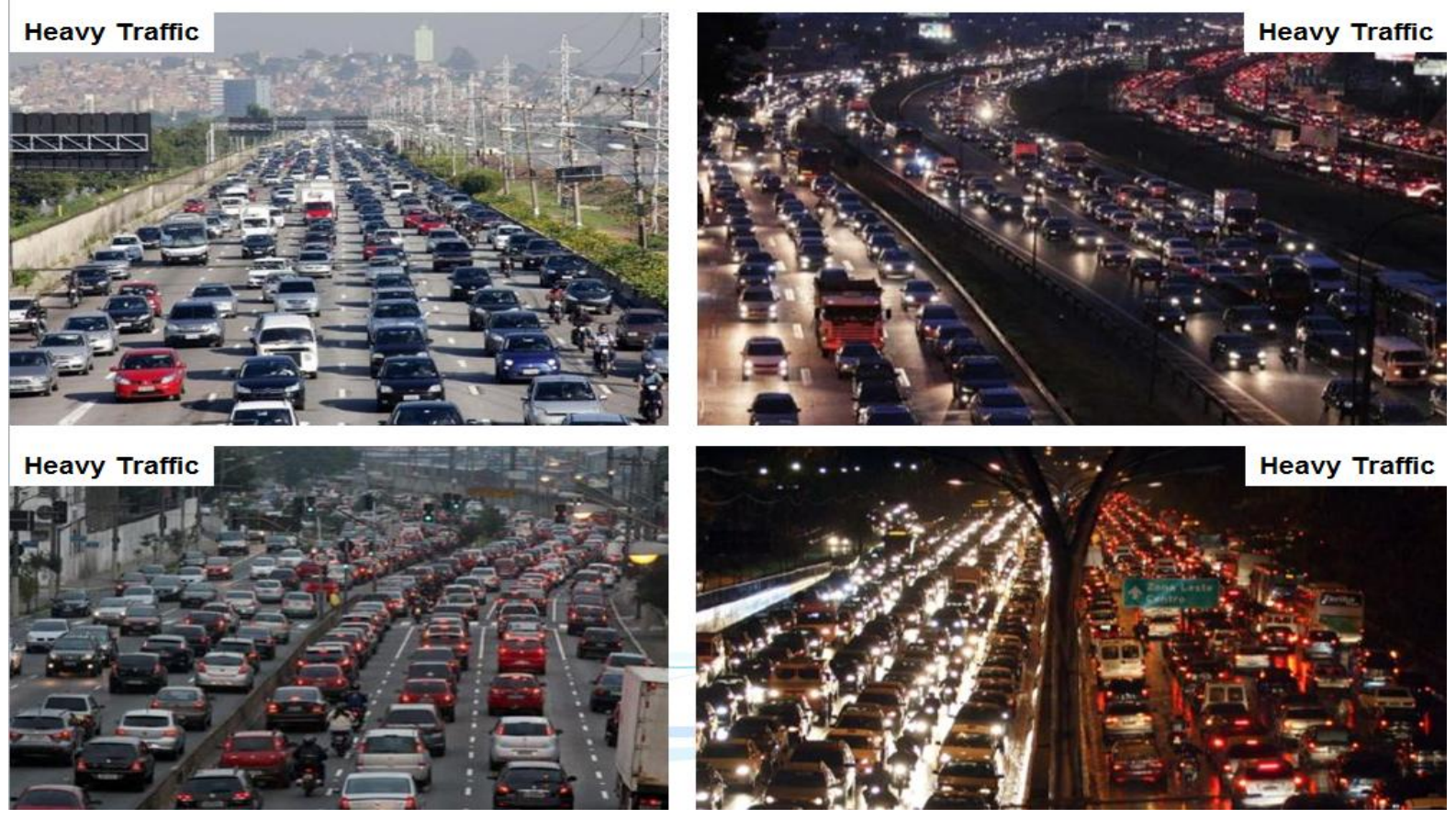

Pictures 44,45,46 \& 47 - Heavy Traffic 
Marcio Caçula is Regional Technical Specialist for Dry Clutch System in South America Region at General Motors Product Engineer Dept - GPS Global Propulsion System. Caçula has 25 years in Car Marker business having worked at Quality, Supplier Quality Engineer \& Manufacturing. Caçula has a graduation at University Braz Cubas \& USP. 